\title{
Sputter deposited titanium oxide layers as efficient electron selective contacts in organic photovoltaic devices
}

Mina Mirsafaei ${ }^{1}$, Pia Bomholt Jensen ${ }^{2}$, Mehrad Ahmadpour ${ }^{1}$, Harish Lakhotiya ${ }^{2}$, John Lundsgaard Hansen ${ }^{2}$, Brian Julsgaard ${ }^{2}$, Horst-Günter Rubahn', Rémi Lazzari ${ }^{3}$, Nadine Witkowski ${ }^{3}$, Peter Balling ${ }^{2}$, Morten Madsen ${ }^{1^{*}}$

${ }^{1}$ SDU NanoSYD, Mads Clausen Institute, University of Southern Denmark, Alsion 2, Sønderborg, DK-6400, Denmark

2 Department of Physics and Astronomy/Interdisciplinary Nanoscience Center (iNano), Aarhus University, Ny Munkegade 120, DK-8000 Aarhus C, Denmark ${ }^{3}$ Sorbonne Université, UMR CNRS 7588, Institut des Nanosciences de Paris (INSP), 4 place Jussieu, 75005 Paris, France

*madsen@mci.sdu.dk

Supplementary Information

\section{External Quantum Efficiency (EQE) measurements}

EQE spectra were measured using a $150 \mathrm{~W}$ Xenon lamp connected to a monochromator (VIS-NIR Newport Cornerstone $1 / 4 \mathrm{~m}$ ), which was connected to a microscope (Mitoyo FS-70) by an optical fiber. The measurement was carried out in air at room temperature, at the wavelength range from $300 \mathrm{~nm}$ to $800 \mathrm{~nm}$. A certified silicon photodiode (Hamamatsu S2386-44 K) was used for calibration at each wavelength. The short-circuit current densities $\left(\mathrm{J}_{\mathrm{sc}}\right)$ calculated from the EQE spectra, figure S1, for OPV cells prepared from $\mathrm{TiO}_{x}\left(355^{\circ} \mathrm{C}\right)$ and $\mathrm{TiO}_{x}\left(155^{\circ} \mathrm{C}\right)$ layers are both $15.9 \mathrm{~mA} / \mathrm{cm}^{2}$, which is in good agreement with the $\mathrm{J}_{\mathrm{sc}}$ extracted from the $\mathrm{J}-\mathrm{V}$ characteristics (Table 1). 


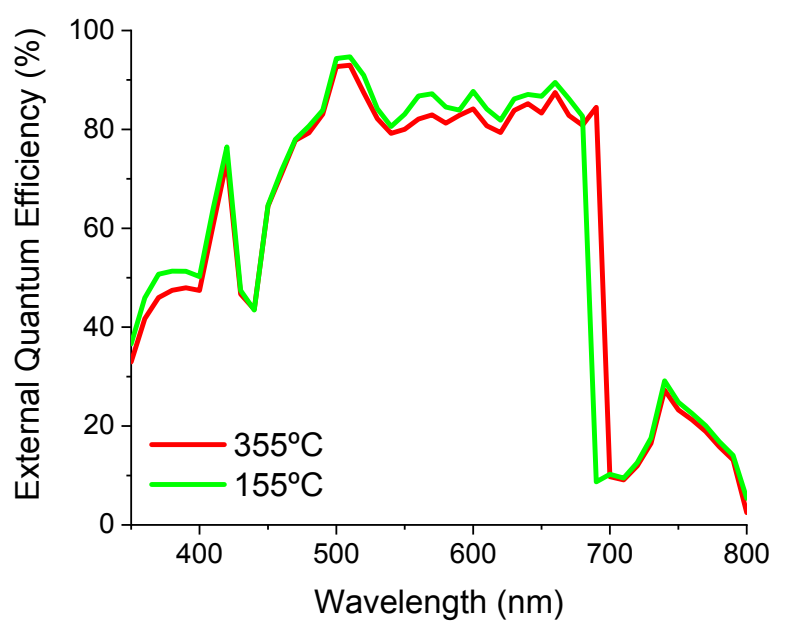

Figure S1: External Quantum Efficiency (EQE) measurements of the PTB7:PC 70 BM solar cells developed with sputtered $\mathrm{TiO}_{x}$ ETL films processed at a substrate temperature of $155^{\circ} \mathrm{C}$ and $355^{\circ} \mathrm{C}$.

\section{Champion OPV cells}

Figure S2 shows JV curves for the $\mathrm{ZnO}$ reference (PCE 8.12\%, $\mathrm{J}_{\mathrm{sc}} 15.25 \mathrm{~mA} / \mathrm{cm}^{2}, \mathrm{~V}_{\text {oc }}$ $736 \mathrm{mV}$ and FF 72.3) and sputtered $\mathrm{TiO}_{\mathrm{x}}, 355^{\circ} \mathrm{C}\left(\mathrm{PCE} 7.65 \%, \mathrm{~J}_{\mathrm{sc}} 16.21 \mathrm{~mA} / \mathrm{cm}^{2}, \mathrm{~V}_{\mathrm{oc}} 724\right.$ $\mathrm{mV}$ and FF 65.2) champion performance cells, demonstrating that although the champion cells are close in performance, the sputtered $\mathrm{TiO}_{x}$ cells suffer from lower FF and slightly lower $\mathrm{V}_{\mathrm{oc}}$ which could be indicative of some additional interface recombination effects taking place in these cells.

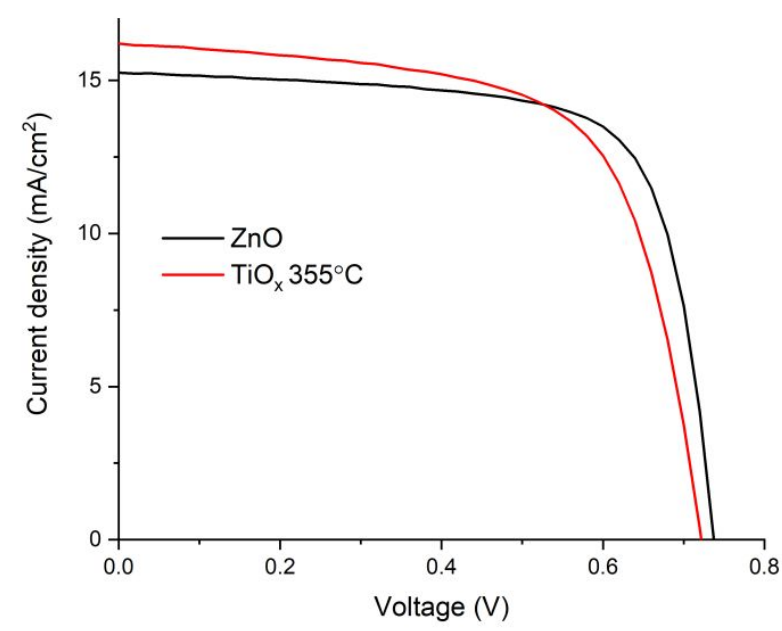

Figure S2: JV curves of champion cells for the $\mathrm{ZnO}$ and $\mathrm{TiO}_{\mathrm{x}}\left(355^{\circ} \mathrm{C}\right)$ based devices. 


\section{Compositional analysis from X-ray photoelectron spectroscopy (XPS)}

The stoichiometry of the $\mathrm{TiO}_{x}$ sputtered sample prepared at $355^{\circ} \mathrm{C}$ (and annealed at $250^{\circ} \mathrm{C}$ to remove contaminants) has been evaluated and compared to the stoichiometry obtained on a single crystal of anatase $\mathrm{TiO}_{2}$, prepared under ultra-high vacuum through sputtering-annealing cycles $\left(1 \mathrm{keV},<500^{\circ} \mathrm{C}\right)$, by using the following procedure. Firstly, all spectra have been processed using CasaXPS software (version 2.3.18) $)^{1}$ to remove $\mathrm{K} \alpha$ satellites present in the original data recorded with nonmonochromatized Al K X-ray source. Secondly, a Shirley type background ${ }^{2}$ has been subtracted from Ti2p and O1s core levels, resulting in the corrected data presented in figure S2a and figure S2b. Corresponding areas of each spectrum have been extracted to estimate the ratio between the two species considering that the photoemission intensity can be expressed as in the case of semi-infinite system (valid for $40 \mathrm{~nm}$ thick films on a photoemission point of view) $)^{3}$ :

$I=J \rho \sigma K \lambda$,

where $\mathrm{J}$ is the photon flux, $\rho$ is the concentration of the atom or ion in the solid, $\sigma$ is the photoionization cross-section (which depends on the element and energy being considered), $\mathrm{K}$ is a term which includes instrumental factors (geometry, solid angle, instrumental efficiency), and $\lambda$ is the electron attenuation length governed by inelastic mean free path of electrons. The ratio of oxygen over titanium $\rho_{\odot} \odot \rho_{\odot \odot} \odot$ has been obtained by using calculated atomic cross sections for photoionization ${ }^{4}$ easily accessible through the periodic table interface developed at Elettra Synchrotron ${ }^{5}$. The inelastic mean free path has been calculated using TPP2M relation ${ }^{6}$ with a band gap of $3.2 \mathrm{eV}, 12$ electrons in the valence shell ${ }^{7}$ and a density of $3.84 \mathrm{~g} / \mathrm{cm}^{3}$ corresponding to single crystal anatase phase ${ }^{8}$. Identical densities have been used for the $\mathrm{TiO}_{\mathrm{x}}$ thin films prepared at $355^{\circ} \mathrm{C}$, which shows a refractive index around 2.6 at $550 \mathrm{~nm}$ that can be correlated to a density very close to the single crystal one. ${ }^{9}$ The instrumental detection efficiency of the spectrometer has been accounted for by considering a transmission factor inversely proportional to the kinetic energy. ${ }^{10}$ Considering a constant photon flux coming from the X-ray sources and all other geometrical considerations kept constant, the stoichiometry of the sample prepared at $355^{\circ} \mathrm{C}$ and post-annealed at $250^{\circ} \mathrm{C}$ is estimated to $\mathrm{TiO}_{x} \mathrm{x}=2.2+/-0.1$ whereas it is found to be $x=2.1+/-0.1$ for the bulk anatase single crystal, prepared as detailed in Ref. $11 .{ }^{11}$ The proportion of oxygen extracted by this procedure for the sputtered thin films prepared at $355^{\circ} \mathrm{C}$ is probably overestimated due to the microstructural nature of the 
TiOx thin films, but it reveals that even if prepared at high temperature, the film stoichiometry remains close to $\mathrm{TiO}_{2}$, and even being slightly super-oxidized. The stoichiometry of the sample sputtered at $155^{\circ} \mathrm{C}$ and post-annealed at about $150^{\circ} \mathrm{C}$ has been estimated to $\mathrm{TiO}_{\mathrm{x}} \mathrm{x}=2.6+/-0.1$ using the same protocol. This value, however, may be significantly overestimated due to a larger residual contamination from carbon and oxygen.
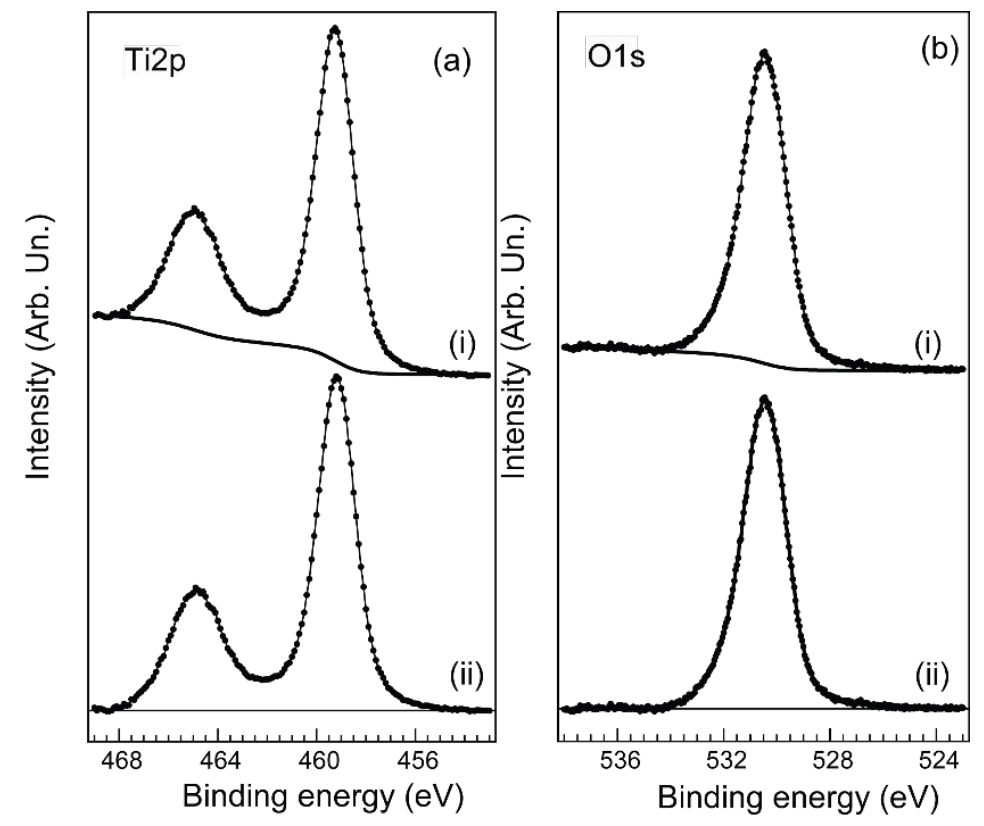

Figure S3: (a) Ti2p (b) O1s core levels raw data (i) and Shirley-background corrected data (ii) for sample prepared at $355^{\circ} \mathrm{C}$ and post-annealed at $250^{\circ} \mathrm{C}$.

\section{XPS fitting parameters}

Spectra were analyzed with CasaXPS software ${ }^{1}$ using Gaussian (40\%) - Lorentzian $(60 \%)$ functions, defined in CasaXPS as GL(60), approximating Voigt function. These profiles were used for each component. The fitting parameters ensuring the best agreement with experimental data are summarized in the Table S1.

Table S1: Fitting parameters for the XPS data.

\begin{tabular}{|l|l|l|l|l|}
\hline & \multicolumn{2}{|c|}{ Main peak } & \multicolumn{2}{c|}{ Shoulder } \\
\hline & Position $(\mathrm{eV})$ & FWHM $(\mathrm{eV})$ & $\begin{array}{l}\text { Position } \\
(\mathrm{eV})\end{array}$ & FWHM $(\mathrm{eV})$ \\
\hline RT sample & 459.00 & 1.77 & 456.03 & 1.37 \\
\hline
\end{tabular}




\begin{tabular}{|l|l|l|l|l|}
\hline $\begin{array}{l}155^{\circ} \mathrm{C} \text { sputtered } \\
\text { sample }\end{array}$ & 459.03 & 1.77 & 456.25 & 1.81 \\
\hline $\begin{array}{l}355^{\circ} \mathrm{C} \text { sputtered } \\
\text { sample }\end{array}$ & 459.18 & 1.68 & 456.11 & 2.01 \\
\hline
\end{tabular}




\section{Bibliography}

(1) Fairley, N., http://www.casaxps.com, (C)asa software Ltd., 2005. No Title.

(2) Shirley, D. A. High-Resolution X-Ray Photoemission Spectrum of the Valence Bands of Gold. Phys. Rev. B 1972, 5 (12), 4709-4714. https://doi.org/10.1103/PhysRevB.5.4709.

(3) Watts, J. F.; Wolstenholme, J. An Introduction to Surface Analysis by XPS and AES; John Wiley \& Sons, Ltd: Chichester, UK, 2003. https://doi.org/10.1002/0470867930.

(4) Parry, D. E. Atomic Calculation of Photoionization Cross-Sections and Asymmetry Parameters J.-J. YEH, Published by Gordon and Breach, Langhorne PA, 1993 ISBN 288124-585-4 Rapid Commun. Mass Spectrom. 1994, 8 (7), 579-579. https://doi.org/10.1002/rcm.1290080716.

(5) Https://vuo.elettra.eu/services/elements/WebElements.html. No Title.

(6) Tanuma, S.; Powell, C. J.; Penn, D. R. Calculation of Electron Inelastic Mean Free Paths (IMFPs) VII. Reliability of the TPP-2M IMFP Predictive Equation. Surf. Interface Anal. 2003, 35 (3), 268-275. https://doi.org/10.1002/sia.1526.

(7) Frandon, J.; Brousseau, B.; Pradal, F. Excitations Électroniques Dans TiO2 Rutile et TiO Mesure Des Pertes d'énergie Des Électrons Entre 3 et 60 EV. J. Phys. 1978, 39 (8), 839846. https://doi.org/10.1051/jphys:01978003908083900.

(8) Ottermann, C. .; Bange, K. Correlation between the Density of TiO2 Films and Their Properties. Thin Solid Films 1996, 286 (1-2), 32-34. https://doi.org/10.1016/S00406090(96)08848-7.

(9) Bundesmann, C.; Lautenschläger, T.; Spemann, D.; Finzel, A.; Thelander, E.; Mensing, M.; Frost, F. Systematic Investigation of the Properties of TiO2 Films Grown by Reactive Ion Beam Sputter Deposition. Appl. Surf. Sci. 2017, 421, 331-340. https://doi.org/10.1016/j.apsusc.2016.08.056.

(10) Brucker, C. F. Electron Spectroscopy: Theory, Techniques and Applications, Vol. 4. C. R. Brundle and A. D. Baker (Editors). Academic Press London, 1982. Surf. Interface Anal. 1982, 4 (6), i-ii. https://doi.org/10.1002/sia.740040611.

(11) Borghetti, P.; Meriggio, E.; Rousse, G.; Cabailh, G.; Lazzari, R.; Jupille, J. Photoemission Fingerprints for Structural Identification of Titanium Dioxide Surfaces. J. Phys. Chem. Lett. 2016, 7 (16), 3223-3228. https://doi.org/10.1021/acs.jpclett.6b01301. 